Reprod. Nutr. Dévelop., 1982, 22 (4), 611-620.

\title{
Rôle du plasma séminal dans la survie in vitro des spermatozoïdes de bouc
}

\author{
J. F. NUNES $\left({ }^{*}\right)$, J.-M. CORTEEL, Y. COMBARNOUS, G. BARIL \\ avec la collaboration technique de $B$. LEBOEUF ${\left({ }^{* *}\right)}^{*}$
}

Station de Physiologie de la Reproduction, I.N.R.A. Nouzilly, 37380, Monnaie, France

(*) EMBRAPA, CNPC, 62100 Sobral, CE, Brasil

(**) I.N.R.A.-S.E.I.A. - 86480 Rouillé, France

\section{Summary. Role of seminal plasma in the in vitro survival of goat sperm.}

The in vitro survival of ejaculated and epididymal goat sperm was measured in a milk diluent while being incubated at $+37{ }^{\circ} \mathrm{C}$ and after having been exposed to seminal plasma or to its components. Non-breeding season seminal plasma had a negative effect on sperm survival whether the cells were cooled to $+20^{\circ} \mathrm{C}$, chilled to $+4{ }^{\circ} \mathrm{C}$ or deepfrozen $\left(-196{ }^{\circ} \mathrm{C}\right)$ before being incubated at $+37^{\circ} \mathrm{C}$. Bulbo-urethral gland secretions also had a deleterious effect on the survival of washed ejaculated and epididymal sperm cooled to $+20^{\circ} \mathrm{C}$. The deleterious effect of the bulbo-urethral secretions on sperm survival and motility was significantly inhibited by the vesicular secretions. Non-breeding season seminal plasma contained bulbo-urethral but little or no vesicular secretions. The non-inhibition of their negative effect(s) may explain that of non-breeding season seminal plasma.

Breeding season and non-breeding season washed ejaculated sperm had a better survival and a better motility than those incubated with breeding season seminal plasma. The mild washing procedure used may be responsible for the incomplete removal of seminal plasma from the sperm environment, namely that of the negative factors of the bulbo-urethral secretions. Breeding season seminal plasma would thus simply inhibit the effect of these negative factors or the factors themselves. This hypothesis is supported by the fact that breeding season seminal plasma had no effect on the survival of epididymal sperm.

When washed ejaculated sperm were exposed to breeding season seminal plasma at $+20^{\circ} \mathrm{C}$ or $+4{ }^{\circ} \mathrm{C}$, it always had a negative effect on post-thaw sperm survival.

\section{Introduction.}

Le plasma séminal diminue la résistance des spermatozoïdes de bouc à la congélation (Corteel, 1974). Cependant, le processus technologique mis en œuvre pour la congélation est lent et les spermatozoïdes se trouvent ainsi soumis aux effets du plasma séminal à des températures relativement élevées, $+37^{\circ} \mathrm{C}$ à $0^{\circ} \mathrm{C}$, pendant plusieurs heures. II nous a paru intéressant d'analyser les effets du plasma séminal sur la survie in vitro des spermatozoïdes, d'une part sans les congeler, d'autre part en les soumettant à la congélation.

La quantité et la qualité des spermatozoïdes récoltés chez les boucs des races européennes présentent une variabilité annuelle marquée (Corteel, 1975 ; 
Corteel, Baril et Lebœuf, 1980). Aussi avons-nous mesuré l'effet de la saison de production du plasma séminal sur la survie des spermatozoïdes éjaculés (motilité et pourcentage de cellules mobiles). Par ailleurs, nous avons utilisé des spermatozoïdes épididymaires sur lesquels nous avons étudié les effets des différents composants du plasma séminal éjaculé : plasma épididymaire, sécrétions vésiculaires et sécrétions bulbo-uréthrales.

\section{Matériel et méthodes.}

A. Spermatozoïdes non soumis à la congélation.

$1 \circ$ Récolte du plasma séminal et des spermatozoïdes éjaculés.

a) Le sperme de trois boucs de race Alpine, âgés de 24-36 mois, a été récolté une à trois fois par semaine au mois d'octobre, à raison d'un éjaculat par jour de récolte. Après mesure du volume de l'éjaculat et de sa concentration en spermatozoïdes, le sperme pur a été centrifugé à température ambiante, à $550 \mathrm{~g}$, pendant $15 \mathrm{~min}$. Le surnageant a fait l'objet d'une seconde centrifugation dans les mêmes conditions. Le deuxième surnageant, appelé plasma séminal de saison sexuelle, a été employé immédiatement ou congelé à $-15{ }^{\circ} \mathrm{C}$ pour une utilisation différée. Les spermatozoïdes contenus dans le culot de la première centrifugation ont été dilués au $1 / 10^{\mathrm{e}}$ (en volume) dans une solution de KrebsRinger phosphate glucose (Corteel, 1974) et centrifugés à $550 \mathrm{~g}$ pendant $15 \mathrm{~min}$ à température ambiante. Après élimination du surnageant, ils ont été remis en suspension $\left(200 \times 10^{6} \mathrm{spz} / \mathrm{ml}\right)$ dans un milieu à base de lait de vache écrémé contenant du glucose (194 $\mathrm{mg}$ pour $100 \mathrm{ml}$ ) (prédiluat).

b) Le plasma séminal et les spermatozoïdes de saison non sexuelle ont été obtenus à partir des mêmes boucs et dans les mêmes conditions, mais aux mois de mars-avril.

$2^{\circ}$ Récolte du plasma et des spermatozoïdes épididymaires. - Onze boucs de race Alpine, âgés de 8 à 36 mois, ont été abattus : sept en saison sexuelle (octobre à janvier) et quatre en saison non sexuelle (février à mai). Le contenu de la partie distale de la queue de l'épididyme a été récupéré par pression manuelle après section du canal épididymaire au niveau de sa jonction avec le canal déférent. La concentration en spermatozoïdes a été mesurée par néphélémétrie. Les préparations des spermatozoïdes et du plasma épididymaires sont semblables à celles décrites pour le matériel éjaculé.

$3^{\circ}$ Récolte du plasma non épididymaire. - Le plasma non épididymaire est obtenu de la même manière que le plasma séminal éjaculé. II est récolté en octobre et avril à partir de deux boucs vasectomisés depuis plus d'un mois.

$4^{\circ}$ Récolte des sécrétions vésiculaires et bulbo-uréthrales. - Les sécrétions vésiculaire et bulbo-uréthrale ont été obtenues par compression des glandes après abattage des animaux et dissection du tractus génital, uniquement pendant la saison sexuelle.

$5^{\circ}$ Traitement des spermatozoïdes. - Dans tous les essais, la concentration en spermatozoïdes des prédiluats a été diminuée de moitié par addition du 
dilueur utilisé pour la prédilution (cf. 1) mais contenant le plasma ou les sécrétions dont les effets étaient recherchés. La concentration finale des diluats en spermatozoïdes a donc été de $100 \times 10^{6}$ par ml. Les quantités de plasma ou de sécrétions utilisées par $\mathrm{ml}$ de diluat ont été de $40 \mu \mathrm{l}$ pour le plasma séminal de boucs entiers ou vasectomisés, de $12,5 \mu$ l pour le plasma épididymaire, de $35 \mu \mathrm{l}$ pour les sécrétions vésiculaires et de $5 \mu \mathrm{l}$ pour les sécrétions bulbo-uréthrales. Ces quantités n'ont pas varié en fonction de la saison de production.

L'incubation a été conduite à $+37^{\circ} \mathrm{C}$ en tubes non bouchés pendant 2 à $4 \mathrm{~h}$ selon les protocoles. Le pourcentage de spermatozoïdes mobiles et leur motilité (notée de 0 à 5) ont été estimés au microscope à contraste de phase, entre lame et lamelle à $+37{ }^{\circ} \mathrm{C}$ par un observateur ignorant la nature des traitements appliqués.

\section{B. Spermatozoïdes éjaculés soumis à la congélation.}

Le sperme a été produit en saison sexuelle par quatre boucs de race Alpine, âgés de 2 à 5 ans. Le plasma séminal et les spermatozoïdes de 32 éjaculats, 18 par bouc), ont été obtenus dans les mêmes conditions que celles décrites précédemment. Quatre traitements ont été appliqués. Pour le lot témoin, le prédiluat de spermatozoïdes lavés a été refroidi à $+4^{\circ} \mathrm{C}$ et la dilution finale a été effectuée avec le dilueur utilisé pour la prédilution mais contenant $14 \mathrm{p} .100$ de glycérol. Le diluat a été congelé à $-196^{\circ} \mathrm{C}$ puis décongelé $48 \mathrm{~h}$ plus tard et incubé a $+37{ }^{\circ} \mathrm{C}$ pendant $2 \mathrm{~h}$. Pour les lots expérimentaux, les spermatozoïdes ont été mis en présence de plasma séminal soit, dès la prédilution, à $+20^{\circ} \mathrm{C}$, soit, lors de la dilution finale, à $+4^{\circ} \mathrm{C}$, soit, immédiatement après décongélation, à $+37^{\circ} \mathrm{C}$.

\section{Résultats.}

A. Spermatozoïdes non soumis à la congélation.

Pendant l'incubation, le taux de spermatozoïdes mobiles et leur motilité diminuent linéairement. II n'existe pas de différence significative de la motilité ou du pourcentage de spermatozoïdes mobiles en fonction de la saison de prélèvement : les valeurs de ces paramètres en début et fin d'incubation sont semblables (tabl. 1), les droites matérialisant leurs diminutions sont

TABLEAU 1

Effet de la saison de récolte sur la survie à $+37^{\circ} \mathrm{C}$ des spermatozoïdes éjaculés et lavés

\begin{tabular}{|c|c|c|c|}
\hline \multirow{2}{*}{ Paramètre estimé } & \multirow{2}{*}{$\begin{array}{c}\text { Moment d'observation } \\
\text { (temps d'incubation } \\
\text { en min) }\end{array}$} & \multicolumn{2}{|c|}{ Spermatozoïdes } \\
\hline & & de saison sexuelle & de saison non sexuelle \\
\hline $\begin{array}{l}\text { Spermatozoïdes mobiles }(\%) \\
(\mathrm{m} \pm \mathrm{sd}) \ldots \ldots \ldots \ldots \ldots \ldots\end{array}$ & $\begin{array}{l}\text { Après } 5 \mathrm{~min} \\
\text { Après } 180 \mathrm{~min}\end{array}$ & $\begin{array}{l}65.7 \pm 7.5 \\
15.0 \pm 8.8\end{array}$ & $\begin{array}{l}67.3 \pm 10.5 \\
11.3 \pm 7.4\end{array}$ \\
\hline Motilité $(0$ à 5$)(m \pm s d) \ldots$ & $\begin{array}{l}\text { Après } 5 \text { min } \\
\text { Après } 180 \text { min }\end{array}$ & $\begin{array}{l}3.3 \pm 0.34 \\
0.8 \pm 0.40\end{array}$ & $\begin{array}{l}3.3 \pm 0.33 \\
0.7 \pm 0.40\end{array}$ \\
\hline
\end{tabular}

$n=12$ pour chaque mesure. Aucune différence significative selon la saison de récolte des spermatozoïdes. Ceux-ci ont été lavés selon la technique de référence (Corteel, 1974) et dilués dans du lait puis mis aussitôt en incubation. Ils n'ont pas été congelés. 

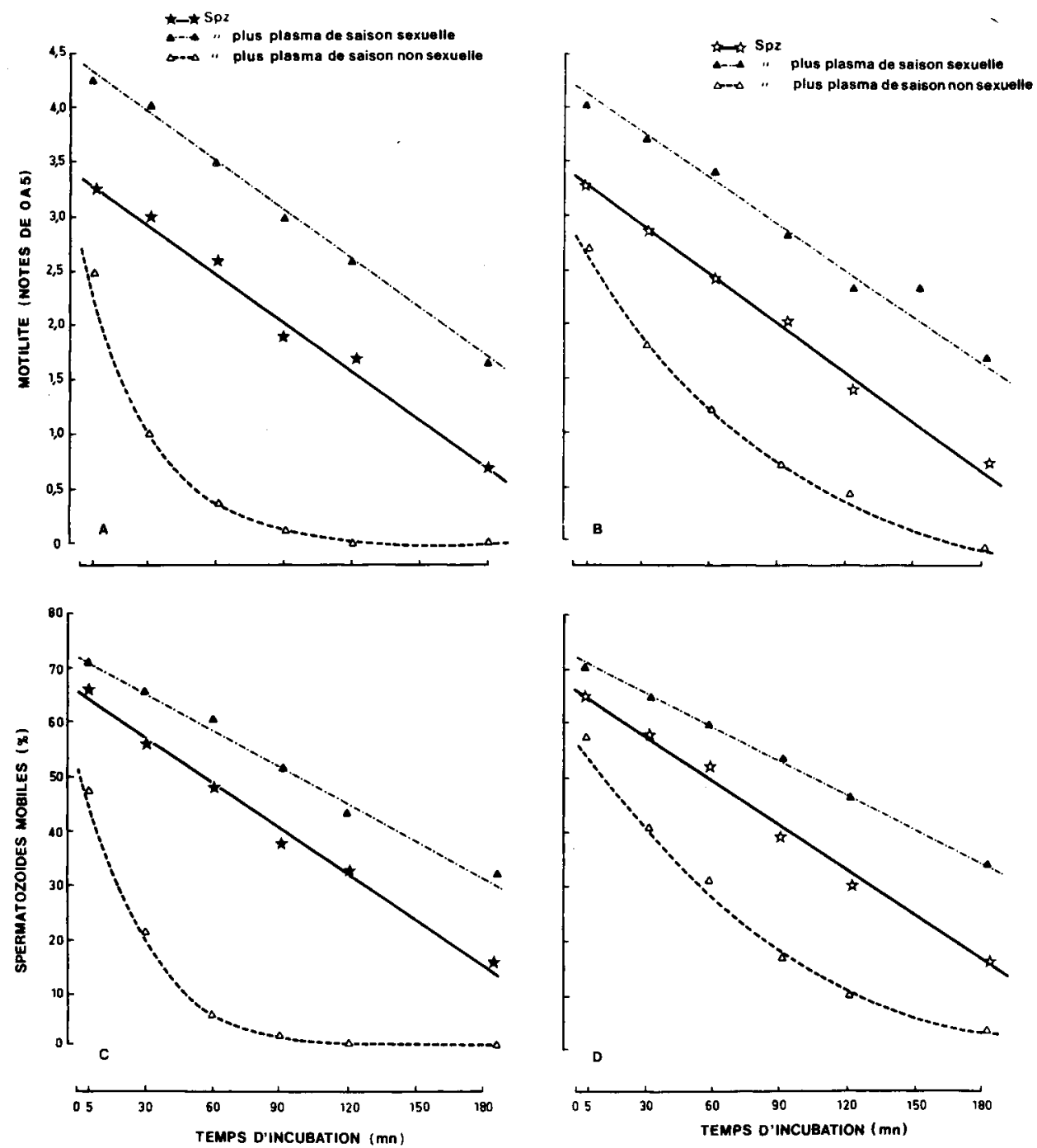

FIG. 1. - Effet du plasma séminal sur la survie des spermatozoïdes ejaculés du bouc selon les saisons de prélèvement. Les observations ont été faites aussitôt la récolte, le lavage et la dilution des spermatozoïdes dans un milieu à base de lait sans qu'ils aient été congelés. A et $C$ : spermatozoïdes de saison sexuelle, $B$ et $D$ : spermatozoides de saison non sexuelle.

superposables (fig. 1). C'est donc au niveau de la composition du plasma séminal qu'il faut rechercher l'origine des variations saisonnières de la survie in vitro des spermatozoïdes des boucs des races européennes.

$1^{\circ}$ Effet du plasma séminal sur les spermatozoïdes éjaculés et lavés.

a) Plasma séminal de saison sexuelle. - Le plasma séminal de saison sexuelle augmente immédiatement la motilité des spermatozoïdes et la maintient environ une heure de plus que chez les spermatozoïdes lavés ne recevant pas de 
plasma séminal, quelle que soit la saison de prélèvement des gamètes $(P<0,05)$ (fig. 1 A et B). Il augmente également le pourcentage de spermatozö̈des mobiles mais l'augmentation visible 5 minutes après décongélation croît légèrement au cours de l'incubation ( $P<0,05)$ (fig. $1 \mathrm{C}$ et $\mathrm{D}$ ).

b) Plasma séminal de saison non sexuelle. - Le plasma séminal de saison non sexuelle entraine une diminution de la motilité et du pourcentage de spermatozoïdes mobiles dès $5 \mathrm{~min}$ d'incubation $(P<0.05)$. Cette diminution s'accélère au cours de la première heure d'incubation, notamment pour les spermatozoïdes de saison sexuelle (fig. 1).

$2^{\circ}$ Spermatozoïdes épididymaires. - La présence dans le milieu de conservation des spermatozoïdes épididymaires de plasma séminal éjaculé en saison non sexuelle, de plasma non épididymaire obtenu en saison non sexuelle, ou en saison sexuelle, provoque une diminution rapide et importante de la motilité et du pourcentage de spermatozoïdes mobiles (fig. 2 et 3 ). Les autres types de plasma ne modifient ni la motilité, ni le pourcentage de spermatozoïdes épididymaires mobiles.
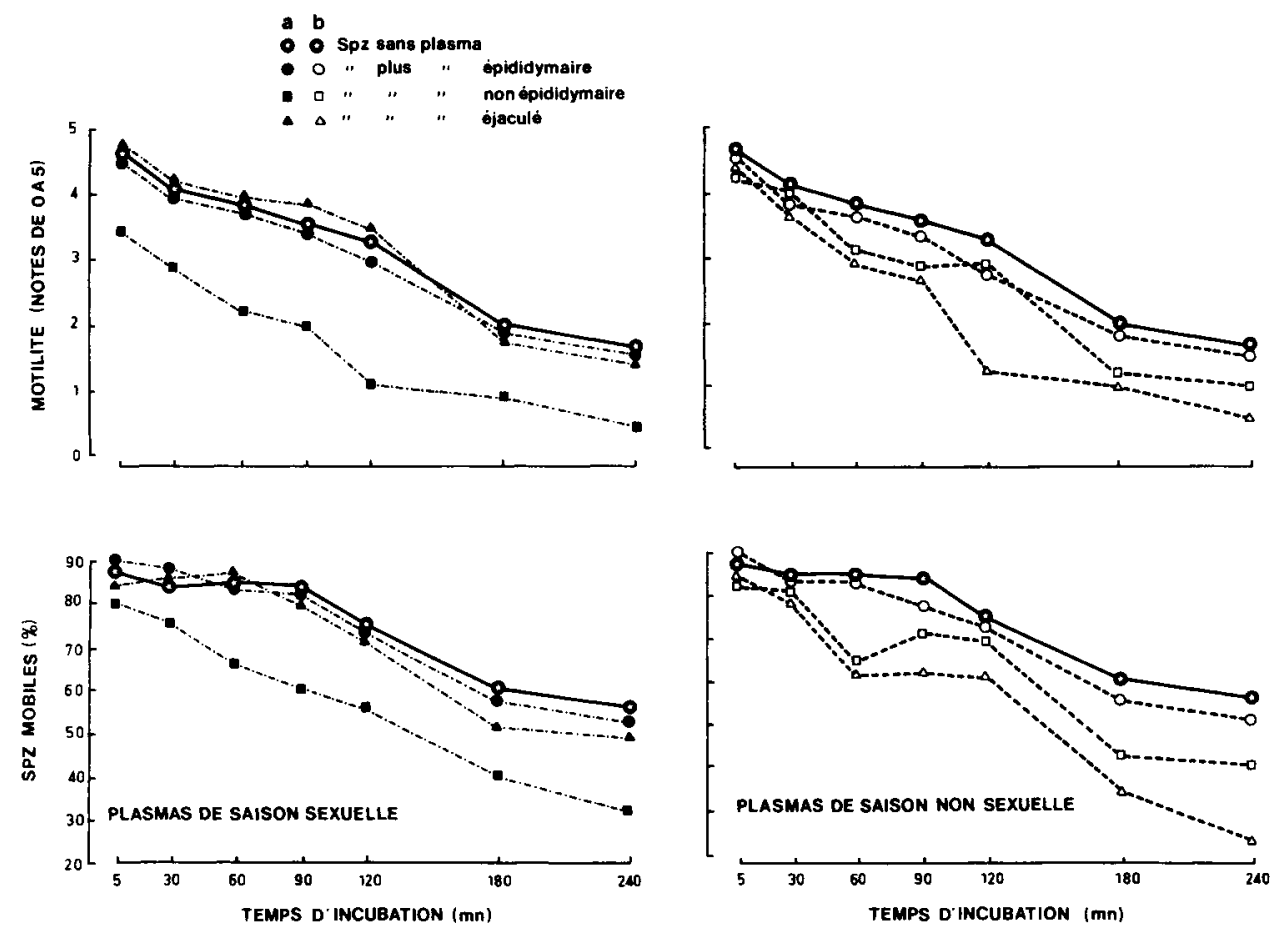

FIG. 2. - Effet de différentes fractions du plasma séminal sur la survie des spermatozoïdes épididymaires de saison sexuelle chez le bouc. Les légendes données sur le graphique correspondent à des fractions obtenues en saison sexuelle (a) et non sexuelle (b). Les observations ont été faites aussitôt la récolte des spermatozoïdes sans qu'ils aient été congelés. 

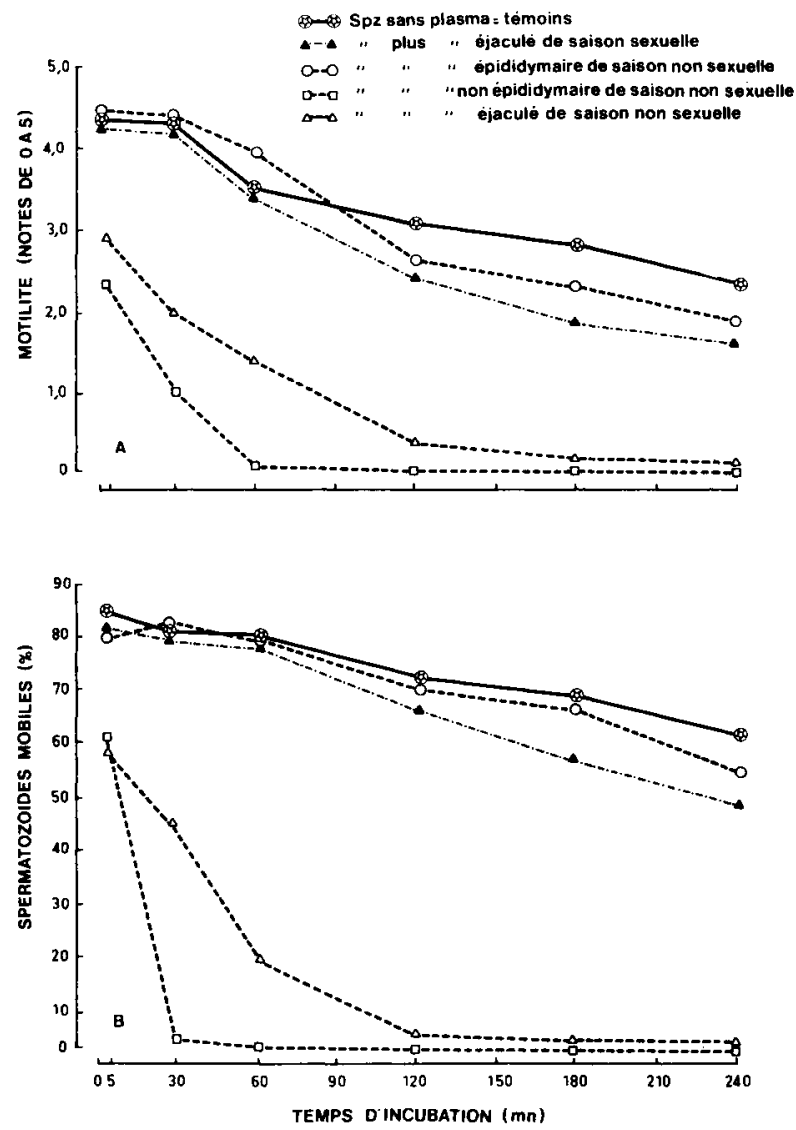

FIG. 3. - Effet de differentes fractions du plasma séminal sur la survie des spermatozoïdes épididymaires de saison non sexuelle chez le bouc.

$3^{\circ}$ Sécrétions des vésicules séminales et des glandes bulbo-uréthrales. Les sécrétions vésiculaires modifient la motilité des spermatozoïdes (fig. $4 \mathrm{~A}$ ). En leur présence, celle-ci est significativement supérieure à celle des témoins après 90 et $120 \mathrm{~min}$ d'incubation; elle ne l'est plus après 180 et $240 \mathrm{~min}$. Les sécrétions bulbo-uréthrales diminuent fortement la motilité : dès $5 \mathrm{~min}$ d'incubation, elle est très significativement inférieure à celle des témoins $(P<0,01)(1,5$ vs 4,5$)$ et devient nulle après 90 minutes d'incubation (fig. $4 \mathrm{~A})$.

Les sécrétions vésiculaires n'affectent pas la survie des spermatozoïdes épididymaires (fig. 4 B). Par contre, les sécrétions bulbo-uréthrales causent une diminution très rapide du pourcentage de cellules mobiles. L'addition simultanée des deux sécrétions n'entraîne une baisse de la survie des spermatozoïdes qu'après 90 min d'incubation (fig. 4 B). 


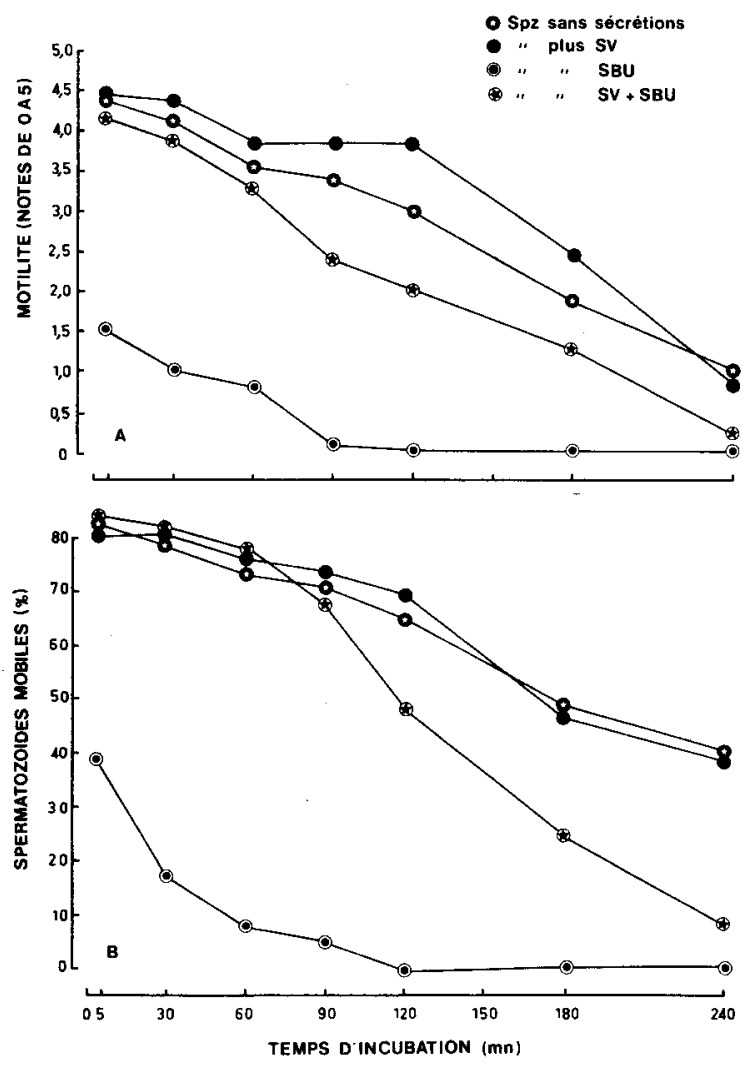

FIG. 4. - Effet des sécrétions des vésicules séminales et des glandes bulbo-uréthrales sur la survie des spermatozoïdes épididymaires du bouc. Expérience faite en saison sexuelle sans congélation du matériel.

\section{B. Spermatozö̈des soumis à la congélation.}

L'addition de plasma séminal de saison sexuelle à des spermatozoïdes de la même saison, éjaculés et lavés, lorsqu'elle est pratiquée sur de la semence prédiluée, à $+20^{\circ} \mathrm{C}$, entraîne une diminution de la motilité et du pourcentage de spermatozoïdes mobiles à chacune des étapes ultérieures de la technologie do la semence (tabl. 2a).

Si l'addition de plasma séminal est faite lors de la dilution finale à $+4{ }^{\circ} \mathrm{C}$, elle provoque encore une diminution de la motilité et du pourcentage de spermatozoïdes mobiles observés après la décongélation de la semence (tabl. 2a). Par contre, aucun effet significatif n'est observé si cette addition est réalisée après la décongélation de la semence. Il semble même y avoir une tendance à une stimulation très légère et transitoire des spermatozoïdes.

Les résultats peuvent aussi être exprimés en pertes relatives de motilité et du pourcentage de spermatozoïdes mobiles au cours de la congélation ou de l'incubation (tabl. 2b). On constate alors que le plasma séminal aggrave les effets nocifs de la congélation et de l'incubation sur le pourcentage de spermatozoïdes mobiles et sur la motilité. 
TABLEAU 2

Effet du plasma séminal de saison sexuelle sur la survie à $+37{ }^{\circ} \mathrm{C}$ des spermatozoïdes bjaculés et lavés de la méme saison

a) Valeurs observées :

\begin{tabular}{|c|c|c|c|c|c|c|}
\hline \multirow{2}{*}{ Traitement } & \multicolumn{2}{|c|}{ A (1) } & \multicolumn{2}{|c|}{ B } & \multicolumn{2}{|c|}{ C } \\
\hline & $\begin{array}{c}\% \text { spz } \\
\text { mobiles }\end{array}$ & Motilité & $\begin{array}{c}\% \text { spz } \\
\text { mobiles }\end{array}$ & Motilité & $\begin{array}{c}\% \text { spz } \\
\text { mobiles }\end{array}$ & Motilité \\
\hline $\begin{array}{l}\text { Témoin (2) } \ldots \ldots \ldots \\
\text { PS (3) à }+20^{\circ} \mathrm{C} \ldots \\
\text { PS à }+4{ }^{\circ} \mathrm{C} \ldots \ldots \ldots \\
\text { PS au dégel } \ldots \ldots \ldots\end{array}$ & $\begin{array}{l}74 \\
66 \\
74(4) \\
74(4)\end{array}$ & $\begin{array}{l}3,3 \\
2,6 \\
3,3(4) \\
3,3(4)\end{array}$ & $\begin{array}{l}44 \\
21 \\
34 \\
50\end{array}$ & $\begin{array}{l}2,6 \\
2,0 \\
2,3 \\
2,8\end{array}$ & $\begin{array}{l}19 \\
04 \\
05 \\
17\end{array}$ & $\begin{array}{l}1,3 \\
0,6 \\
0,6 \\
1,1\end{array}$ \\
\hline
\end{tabular}

b) Pertes (en \%) causées par :

\begin{tabular}{lccccc}
\hline \multirow{2}{*}{ Traitement } & \multicolumn{2}{c}{ la congélation (5) } & \multicolumn{2}{c}{ l'incubation (5) } \\
\cline { 2 - 6 } & \% spz mobiles & Motilité & \% & spz mobiles & Motilité \\
\hline Témoin $\ldots \ldots \ldots \ldots \ldots$ & 41 & 21 & 57 & 50 \\
PS à $+20^{\circ} \mathrm{C} \ldots \ldots \ldots \ldots$ & 68 & 23 & 81 & 70 \\
PS à $+4{ }^{\circ} \mathrm{C} \ldots \ldots \ldots \ldots$ & 54 & 30 & 85 & 74 \\
PS au dégel $\ldots \ldots \ldots \ldots$ & - & - & 66 & 61 \\
\hline
\end{tabular}

(1) Moment d'observation des spermatozoïdes au cours de leur préparation, A : après refroidissement à $+4{ }^{\circ} \mathrm{C}$ et addition glycérol; $B: 5 \mathrm{mn}$ après dégel; $\mathrm{C}: 120 \mathrm{mn}$ après dégel, $\mathrm{n}=8$ : 4 boucs, 2 éjaculats par bouc.

(2) Témoin : spermatozoïdes dilués dans du lait selon la technique de référence (Corteel, 1974).

(3) PS : plasma séminal éjaculé, $40 \mu \mathrm{l}$ ajoutés à $1 \mathrm{ml}$ du sperme dilué.

(4) Ces valeurs sont par définition les mêmes que celles du lot témoin.

(5) Les pertes sont exprimées par les rapports $\frac{A-B}{A} \times 100$ pour ce qui est dû à la congélation et $\frac{B-C}{B} \times 100$ pour ce qui est dû à l'incubation.

\section{Discussion.}

Lors de travaux antérieurs, nous avions constaté que l'élimination du plasma séminal du sperme éjaculé par lavage des spermatozoïdes entraînait, en toutes saisons, une amélioration du pourcentage de spermatozoïdes mobiles et de leur motilité après décongélation (Corteel, 1974; Corteel et Lebœuf, 1979). En complément, nous montrons ici que l'incorporation de plasma séminal de saison sexuelle dans le milieu de conservation des spermatozoïdes éjaculés et lavés diminue leur aptitude à supporter la congélation (tabl. 2). L'effet négatif du plasma séminal sur l'aptitude à la congélation des spermatozoïdes éjaculés conservés dans un milieu à base de lait de vache écrémé est ainsi solidement établi.

L'effet négatif du plasma séminal de saison non sexuelle sur la survie et la motilité des spermatozoïdes éjaculés, lavés et non refroidis est pratiquement 
immédiat et va en s'aggravant (fig. 1); ceci peut expliquer qu'il soit si néfaste pour la survie et la motilité des spermatozoïdes éjaculés soumis à la congélation (Corteel, 1981). Par contre, nos résultats montrent que le plasma séminal de saison sexuelle a un effet positif sur la survie des spermatozoïdes éjaculés, lavés et non refroidis (fig. 1). Celui-ci est pratiquement immédiat mais ne varie plus ensuite. Cependant, cet effet s'accompagne d'une modification des spermatozoïdes qui entraîne leur moindre résistance à la congélation, comme le montre l'expérience rapportée au tableau 2. La nature de cette modification n'est pour l'instant pas connue.

L'utilisation de spermatozoïdes épididymaires qui n'ont jamais subi l'action des sécrétions des glandes annexes permet une étude du rôle de celles-ci.

Les figures 2 et 3 montrent que le plasma séminal de saison non sexuelle présente un effet négatif très marqué alors que le plasma séminal de saison sexuelle n'a pas d'effet sur le maintien de la motilité et de la survie des spermatozoïdes épididymaires. Des différences existent selon les espèces puisque dans des conditions comparables Dott et al. (1979) observent une stimulation de la motilité des spermatozoïdes épididymaires du Taureau et du Bélier par le plasma séminal de saison sexuelle. Notre analyse a été poussée plus avant par le recours aux produits des glandes bulbo-uréthrales et vésiculaires. Les sécrétions des glandes bulbo-uréthrales ont un effet très négatif sur la survie des spermatozoïdes épididymaires (fig. 4). Les sécrétions vésiculaires ont une action positive sur la motilité des spermatozoïdes, mais elles sont sans effet sur le pourcentage de spermatozoïdes mobiles (fig. 4). En outre, elles inhibent en partie l'effet négatif des sécrétions bulbo-uréthrales. On a observé que pendant la saison sexuelle, les sécrétions vésiculaires constituent en volume la plus grande part du plasma séminal éjaculé (Nunes, observation personnelle) et que le volume de l'éjaculat et la motilité après vésiculectomie sont très réduits chez le bouc (Corteel et Baril, 1976). On peut donc suggérer que l'effet négatif des sécrétions bulbo-uréthrales sur la motilité des spermatozoïdes est inhibée partiellement pendant la saison sexuelle, par l'apport important des sécrétions vésiculaires, ce qui $n^{\prime}$ est pas le cas en saison non sexuelle.

L'effet négatif observé avec le plasma non épididymaire de saison sexuelle sur les spermatozoïdes épididymaires peut paraître discordant dans le cadre de cette hypothèse. Cependant, le plasma non épididymaire que nous avons utilisé provient de boucs vasectomisés depuis plus d'un mois. Or, il a été montré que cette opération entraîne chez l'homme et le rat une diminution significative de la testostéronémie (Adamopoulos et al., 1973 ; Sackler et al., 1973) et on sait que, chez le bouc, les sécrétions vésiculaires sont dépendantes des androgènes (Leidl, 1958 ; Iritani et Nishikawa, 1964). II est donc possible que la composition du plasma non épididymaire de boucs vasectomisés diffère de celle de la fraction non épididymaire du plasma séminal éjaculé par des boucs non vasectomisés.

\section{Conclusion.}

Nous avons établi l'existence d'un (ou de) facteur(s) négatif(s) provenant des glandes bulbo-uréthrales sur la motilité des spermatozoïdes épididymaires ou 
éjaculés. L'effet de ce(s) facteur(s) sur la motilité peut être inhibé par les sécrétions vésiculaires de saison sexuelle. II est peu probable, cependant, que leur rôle ne concerne que la motilité des gamètes. En effet, la fertilité des spermatozoïdes épididymaires du bouc est mauvaise malgré leur bonne motilité (Haller, Chemineau et Corteel, 1980). A l'inverse, les spermatozoïdes éjaculés et lavés de saison sexuelle présentent une bonne fertilité malgré une motilité souvent inférieure. Ceci indique que l'action des sécrétions des glandes annexes ne s'exerce.pas uniquement sur la motilité mais provoque vraisemblablement d'autres changements qualitatifs importants des spermatozoïdes.

Indépendamment des hypothèses physiologiques suggérées par l'ensemble de nos résultats, on comprend mieux la nécessité du lavage des spermatozoïdes éjaculés pour leur conservation par congélation. II apparaît toutefois souhaitable d'analyser plus en détail les modifications subies par les spermatozoïdes et les mécanismes qui en rendent compte.

Reçu en avril 1981.

Accepté en janvier 1982.

\section{Références}

ADAMOPOULOS D. A., LAWRENCE D. M., SWYER G. I. M., 1973. Testosterone concentration in the semen of normospermic, oligospermic azoospermic and vasectomized subjects. Acta Endocrinol. (Kbh), Suppl. 177, Abstr. 59.

CORTEEL J. M., 1974. Viabilité des spermatozoïdes de bouc conservés et congelés avec ou sans leur plasma séminal : effet du glucose. Ann. Biol. anim. Bioch. Biophys., 14, 741-745.

CORTEEL J. M., 1975. Production de sperme chez le bouc: variation saisonnière de la quantité et de la qualité du sperme récolté selon l'âge des animaux. C.R. Journées de la Recherche ovine et caprine, Paris, I.N.R.A.-I.T.O.V.I.C. Ed., 1, 4-17.

CORTEEL J. M., 1981. Collection, processing and artificial insemination of goat semen. In C. GALL, Goat production. Acad. Press Inc. (Lond.) Ltd, Chapt. 5, 171-191.

CORTEEL J. M., BARIL G., 1976. Effets de la vésiculectomie sur le volume de l'éjaculat, sa concentration en spermatozoïdes et l'aptitude de ces derniers à supporter la congélation (résultats non publiés).

CORTEEL J. M., BARIL G., LEBOEUF B., 1980. Residual seasonal variations in fertility in selected deep-frozen ejaculates of European dairy male goats. Proceed. 9th int. Congr. anim. Reprod. artif. Insem., Madrid, III, (Abstr.).

CORTEEL J. M., LEBOEUF B., 1979. La survie des spermatozoïdes de bouc éjaculés, congelés et dégelés de saison non sexuelle (résultats non publiés).

DOTT H. M., HARRISON R. A. P., FOSTER G. C. A., 1979. The maintenance of motility and the surface properties of epididymal spermatozoa from bull, rabbit and ram in homologous seminal and epididymal plasma. J. Reprod. Fert., 55, 113-124.

HALLER O., CHEMINEAU P., CORTEEL J. M., 1980. In vitro survival and fertilizing ability of goat epididymal sperm. Proceed. 9th int. Congr. anim. Reprod. artif. Insem., Madrid, III, 316 (Abstr.).

IRITANI A., NISHIKAWA Y., 1964. Studies on the egg-Yolk coagulating enzyme in goat semen. VI. On the chemical properties of the ejaculated semen and the secretion of accessory sexuel organs in the goat. $J$. anim. Reprod., 10, 44-51.

LEIDL W., 1958. Klima und Sexual funktion mannlicher Haustiere. M. und H. Schaper Ed., Dissertation, Hannover.

SACKLER A. M., STANLEY A., PANDHI V., SCHWARTZ R., 1973. Gonadal effects of vasectomy and vasoligation. Science, 179, 293-295. 